DOI 10.20396/temáticas.v28i55.14027

\title{
ENSAIO FOTOGRÁFICO
}

\section{PERFORMANDO COM A COVID-19+: ( $2^{\circ}$ MOVIMENTO)}




\title{
UM FUTURO POSSÍVEL: PERFORMANDO COM A COVID-19+
}

\author{
Silvia Cristina dos Reis ${ }^{1}$ \\ Thais de Almeida Gonçalves ${ }^{2}$
}

RESUMO: O presente ensaio traz imagens do ato Performando com a Covid-19+: ( $2^{\circ}$ movimento) e conduz a uma reflexão sobre um futuro ainda incerto.

PALAVRAS-CHAVE: Performace. Fotografias. Covid-19.

\section{A POSSIBLE FUTURE: PERFORMING WITH COVID-19+}

ABSTRACT: The present essay brings images of the act Performando com Covid-19+: (2nd movement) and leads to a reflection on an uncertain future.

KEYWORDS: Perform. Photography. Folklore. Covid-19.

\section{UN FUTURO POSIBLE: PERFORMANDO CON COVID-19+}

RESUMEN: El presente ensayo trae imágenes del acto Performando com Covid-19 +: ( $2^{\circ}$ movimiento) y conduce a una reflexión sobre un futuro incierto.

PALABRAS CLAVE: Performace. Fotografía. Folclore. Covid-19.

\footnotetext{
${ }^{1}$ Mestrado Interdisciplinar em Artes, Urbanidades e Sustentabilidade pela Universidade Federal São João del-Rei. Pesquisa financiada pela Coordenação de Aperfeiçoamento de Pessoal de Nível Superior do Ministério da Educação e Cultura. Contato: tudocinzagrafitte@gmail.com. ${ }^{2}$ Mestrado Interdisciplinar em Artes, Urbanidades e Sustentabilidade pela Universidade Federal de São João del-Rei. Contato: thais.dagoncalves@gmail.com
} 
A pandemia da Covid-19 tem modificado significativamente o comportamento das pessoas. Em alguns lugares do mundo governantes tentam minimizar os efeitos dessa doença na sociedade, enquanto em outros lugares têm se enfatizado a gravidade do problema e a importância das medidas de prevenção. Nesse panorama, muito se discute sobre uma nova forma de se estar na rua, a partir do que se tem denominado como "novo normal".

Em um cenário dicotômico entre os crentes e descrentes das evidências científicas dessa doença, no qual todos os dias é preciso reafirmar as medidas de isolamento social, bem como o uso de máscaras e a higienização das mãos, o ato Performando com a Covid-19+: $\left(2^{\circ} \text { movimento }\right)^{3}$ conduz a uma reflexão sobre um futuro ainda abstrato: o que nos espera na pós-pandemia? Haverá de fato uma pós-pandemia?

Essa ação, - iniciativa do Laboratório de Ecopoéticas da Universidade Federal de São João del-Rei (UFSJ), coordenado pelo professor Adilson Siqueira - no instante da sua execução, provocou os mais variados questionamentos da população são-joanense que transitava pela área central da cidade. Alguns expressados de forma oral: "Isso é coisa da prefeitura para as pessoas usarem máscara"; "Nossa, que susto!"; "Isso é um deboche com os são-joanenses"; "Palhaçada!"; "Olha a Covid aiiiiiiiii”. As variadas reações, como mudar de calçada, olhar com espanto e buzinar etc., evidenciam o quão anormal ainda é lidar com essa temática.

A performance se dá no aqui e agora, no momento da copresença em espaço e tempo reais, de performer e de seu público (cf. MATESCO, 2012). Contudo, a fotografia pode eternizar esse momento e instigar outros questionamentos, já que ela, além de informar, deixa espaço para imaginar. Sendo assim, este ensaio fotográfico convida os apreciadores a refletirem sobre os momentos retratados nestas imagens: um futuro possível em um país, como o Brasil, que encontrou grandes obstáculos para administrar devidamente esta pandemia, e parece ignorar as evidências científicas contra esse inimigo invisível que é o SARS-CoV-2.

\footnotetext{
${ }^{3}$ Realizada pelo performer Glauco Manuel dos Santos.
} 


\section{SOBRE AS FOTOS}

Título: Performando com a Covid-19+: (2 movimento). 24 de julho de 2020. Autoria: Silvia Cristina dos Reis.

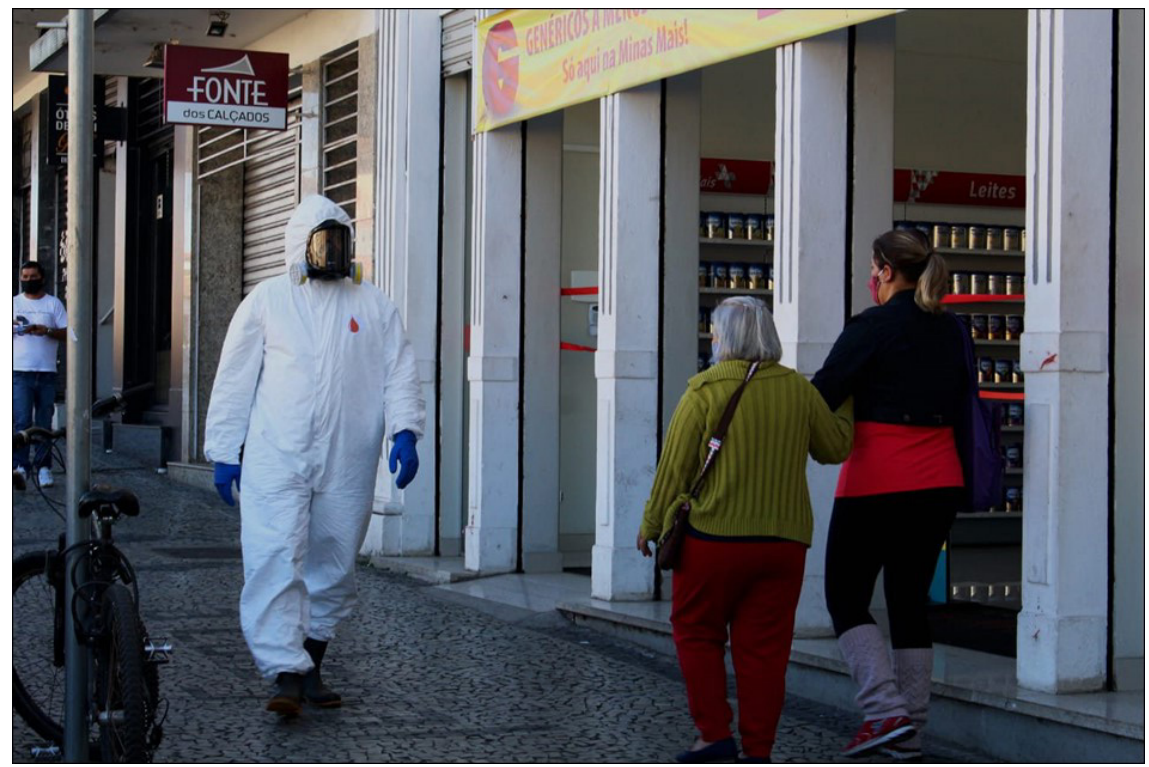

Foto - 01 


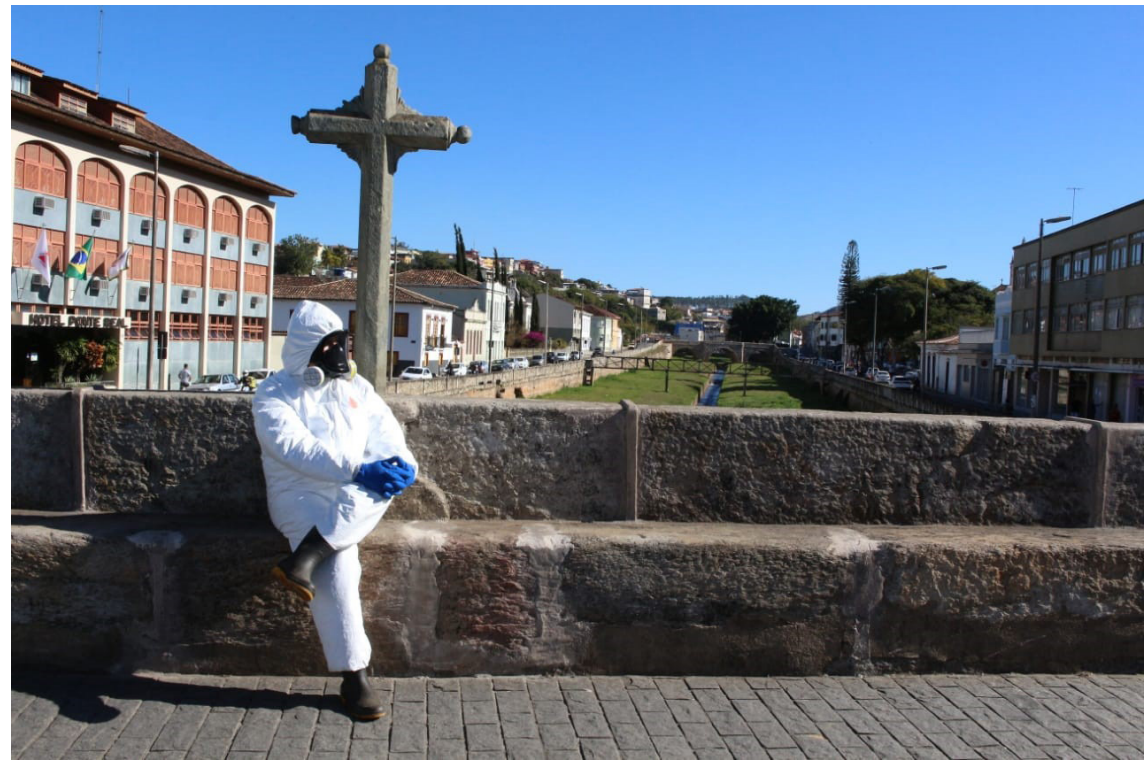

Foto - 02

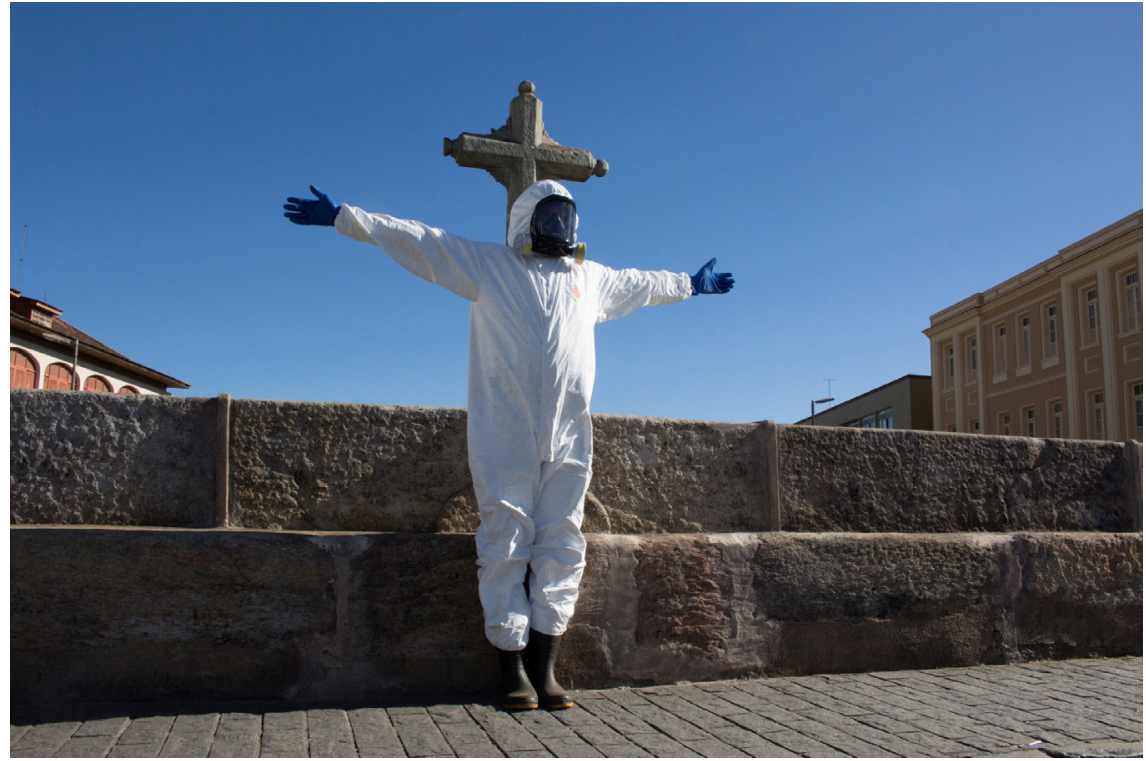

Foto - 03

Temáticas, Campinas, 28, (55): 391-399, fev./jun. 2020 


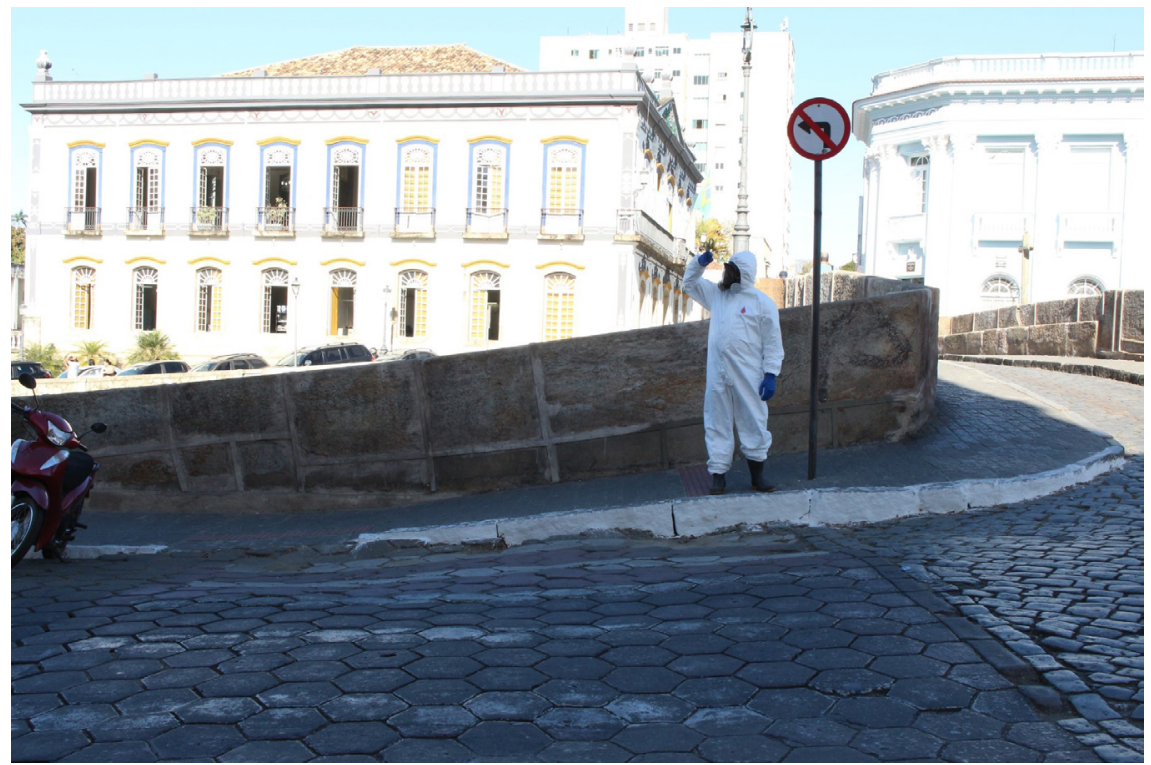

Foto - 04

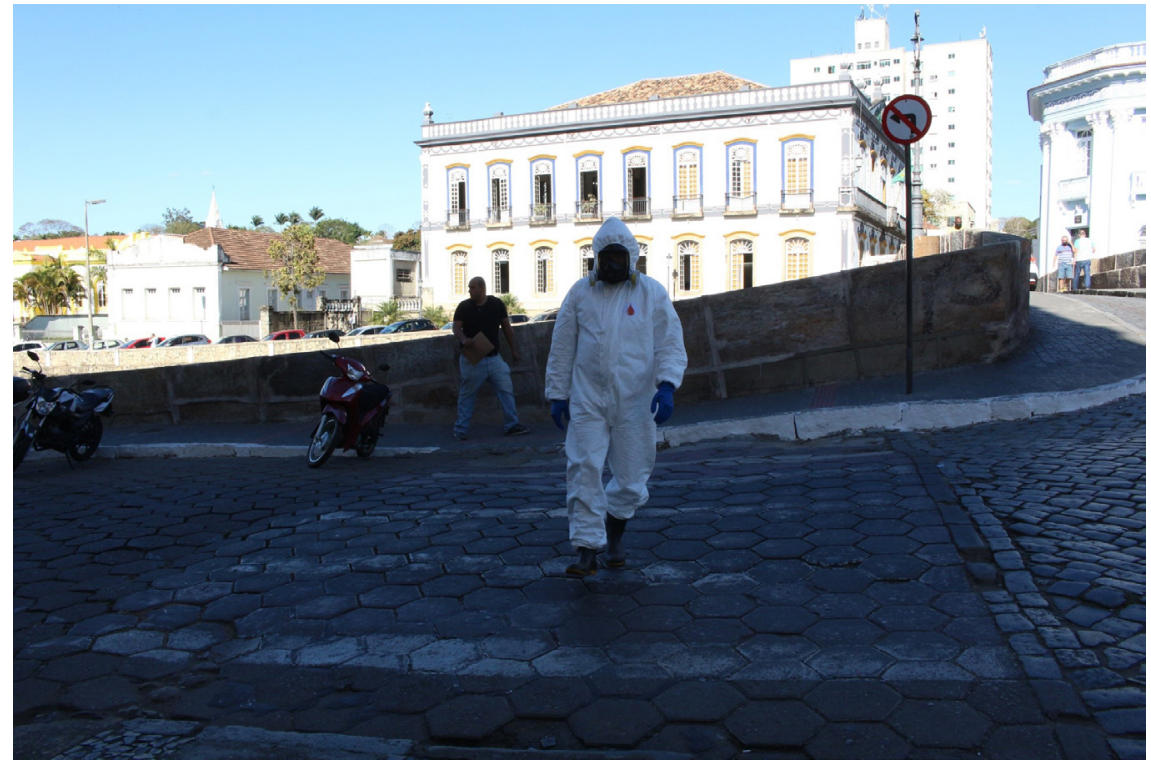

Foto - 05

Temáticas, Campinas, 28, (55): 391-399, fev./jun. 2020 


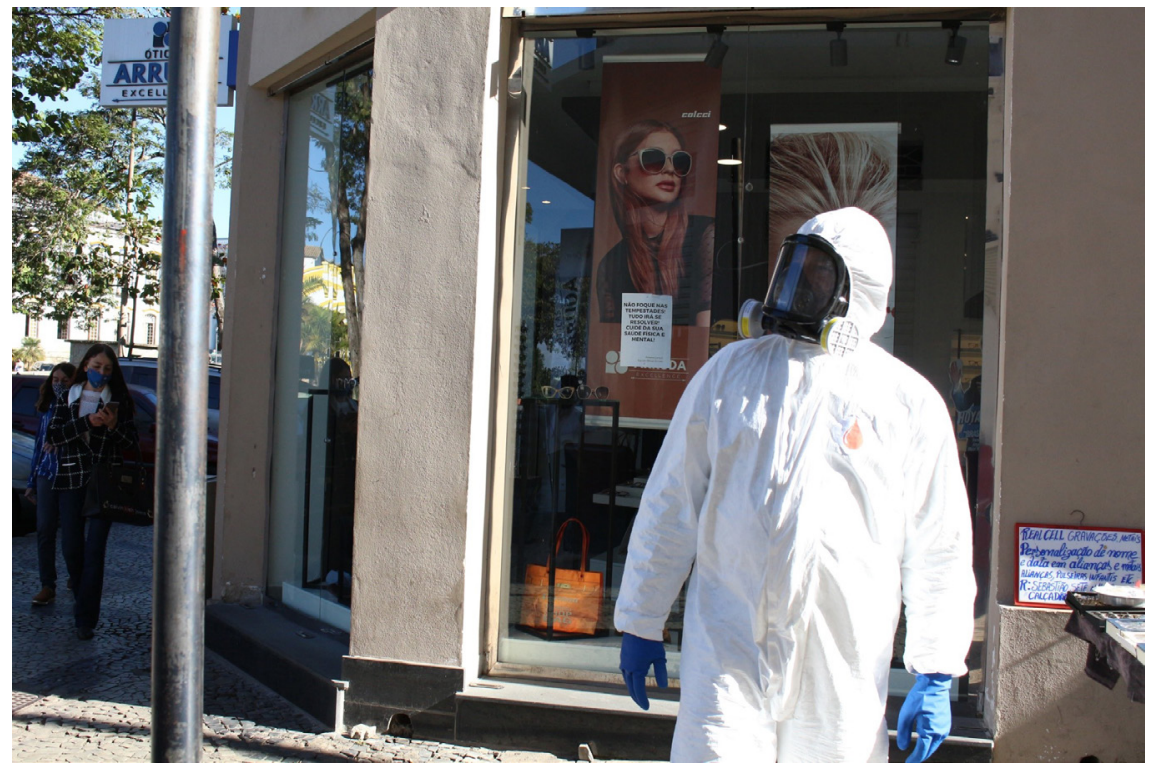

Foto - 06

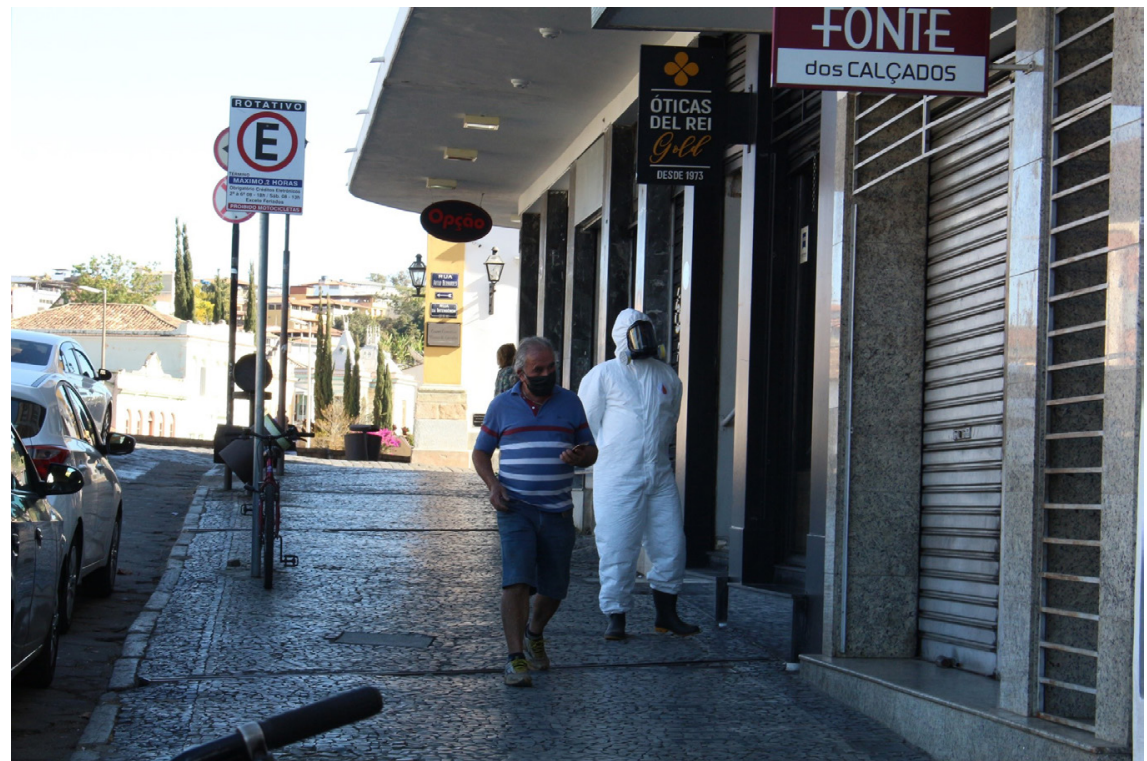

Foto - 07 


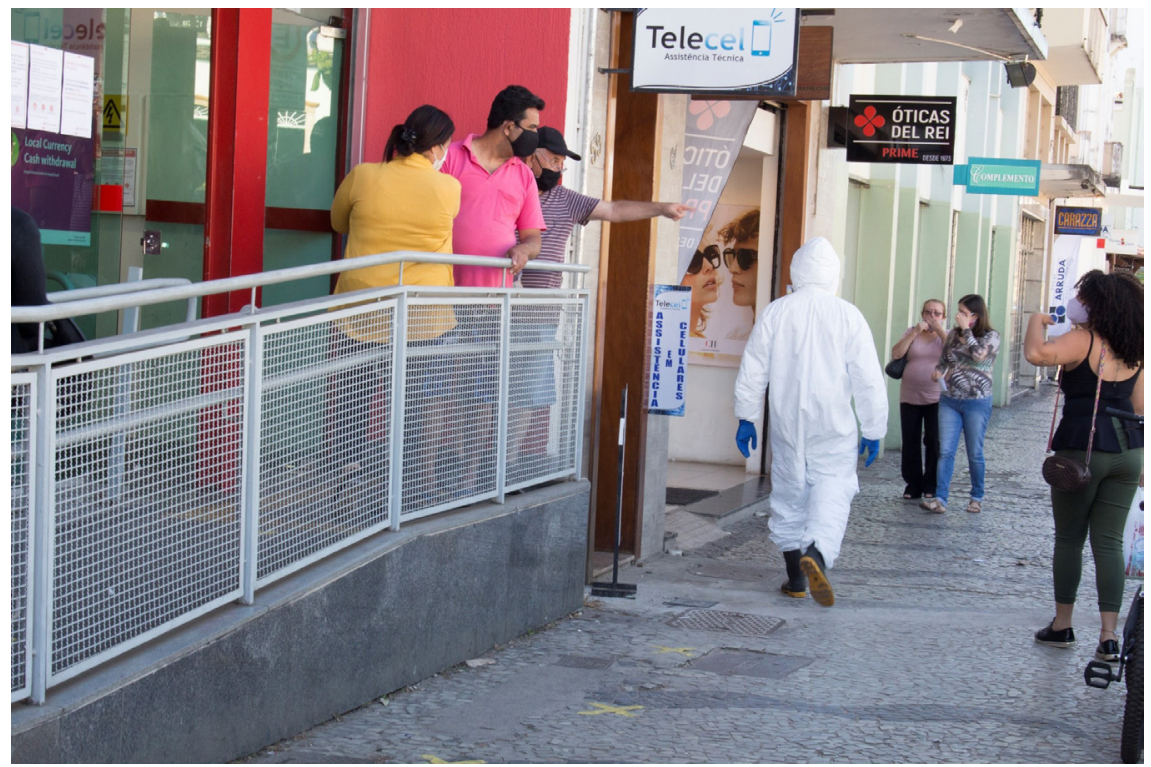

Foto - 08

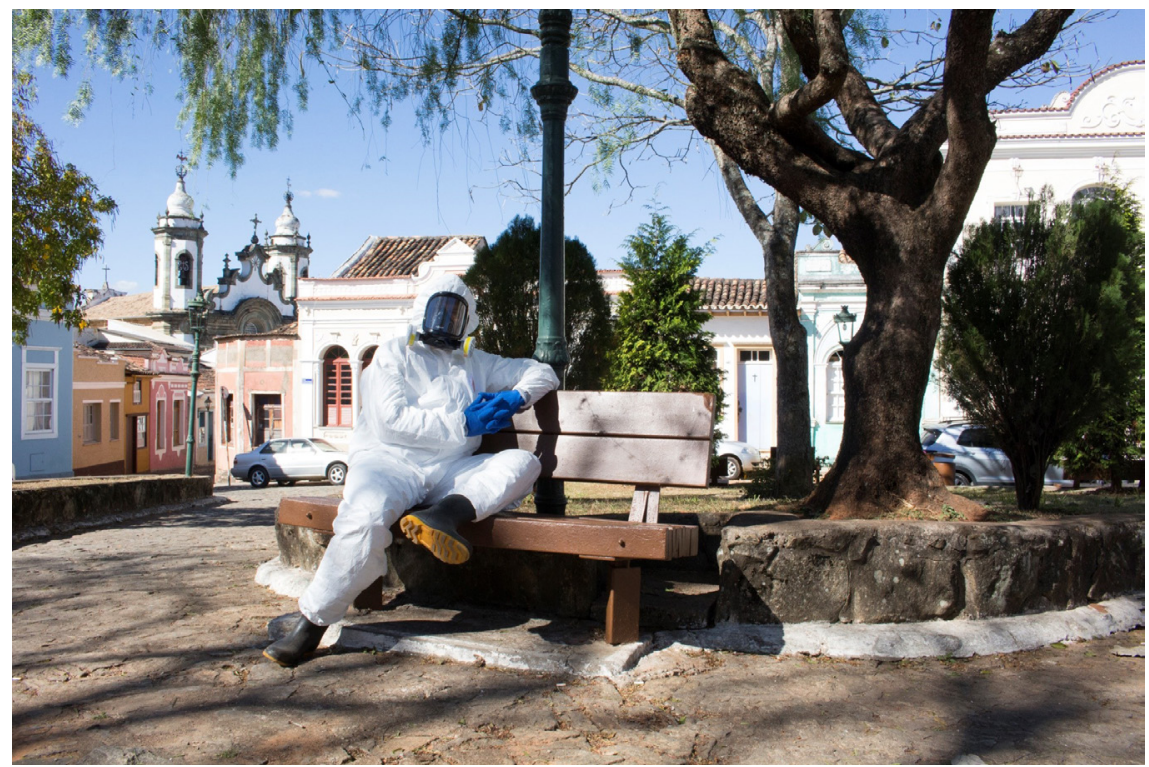

Foto - 09

Temáticas, Campinas, 28, (55): 391-399, fev./jun. 2020 


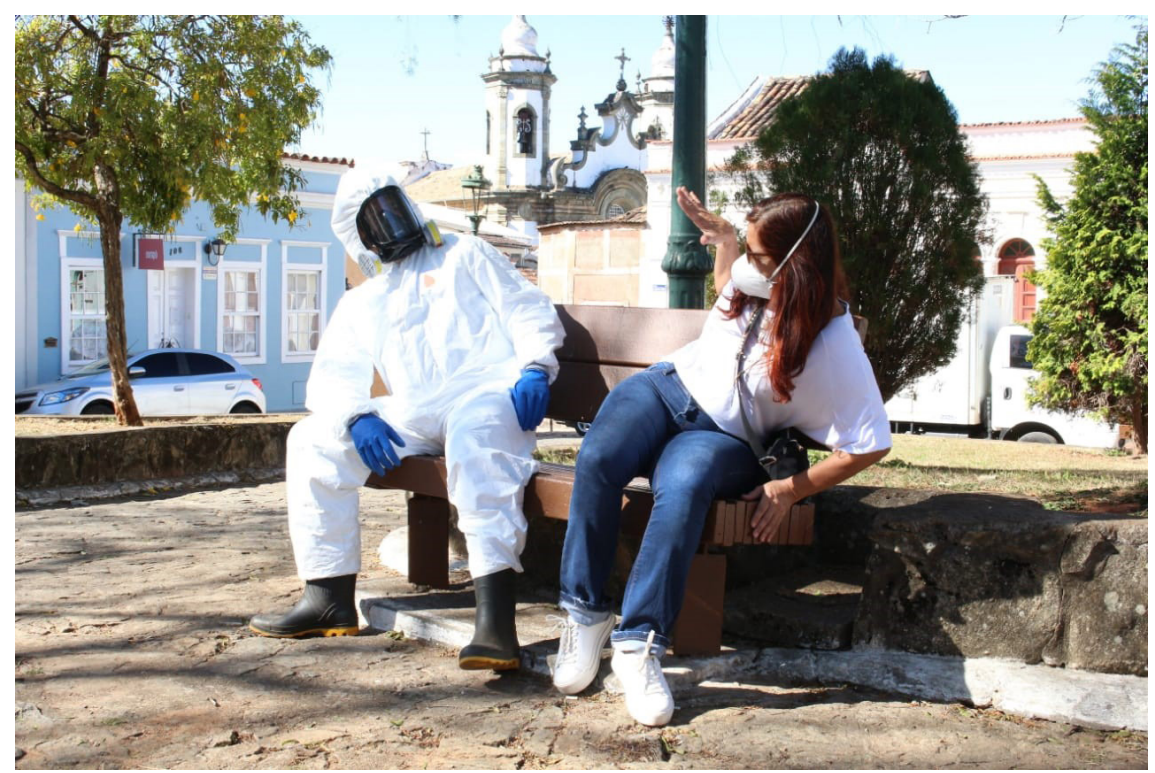

Foto - 10

\section{REFERÊNCIAS BIBLIOGRÁFICAS}

MATESCO, Viviane. "Corpo, ação e imagem: consolidação da performance como questão”. Revista Poiésis. v. 13, n. 20, dez. de 2012, p. 105118. Disponível em: <https://periodicos.uff.br/poiesis/article/ view/26901/15612>. Acesso em: 30 de ago. de 2020. 